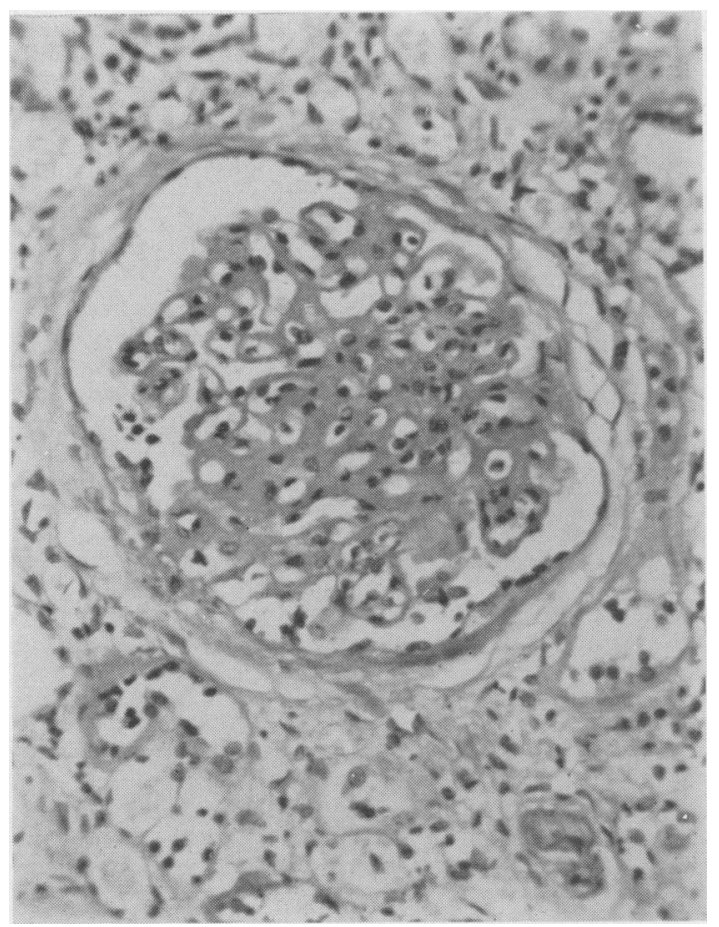

FIG. 6.--Histological appearances of kidney at postmortem.

a traumatic thrombosis of the right femoral vein which spread to involve the inferior vena cava and the renal veins producing a nephrotic syndrome. The histological appearances of the renal biopsy one year after the initial injury showed that gross renal changes had by then developed. The autopsy demonstrated that the inferior vena cava and renal veins had recanalised either naturally or as a result of anticoagulant therapy and the histology of the venous bands suggested that this occurred a long time before death. The clinical course and the postmortem findings indicated that despite this restoration of venous outflow from the kidneys the renal glomerular lesions had progressed and that renal function became further impaired by pyelonephritis and ischæmic changes secondary to hypertension.

The only therapeutic measures which appeared to have any beneficial effect were the high protein feeding which despite heavy proteinuria restored the serum albumin to levels sufficient to prevent hypoproteinæmic œdema, and sulphonamides and antibiotics which controlled secondary pyelonephritis. As in other patients with nephrotic syndrome associated with renal vein thrombosis which we have treated, steroid therapy failed to diminish urinary protein loss. To what extent anticoagulants were responsible for the recanalisation of the inferior vena cava and the renal veins it is impossible to say but they certainly did not halt the inexorable march of renal destruction.

We are greatly indebted to Dr. J. F. Soothill for the immunochemical clearances.

\section{REFERENCES}

Blainey, J. D., BreWer, D. B., HardWicke, J., and Soothill, J.' F. (1960): The Nephrotic Syndrome, Quart. J. Med., 29, 235.

BLAINEY, J. D., HARDWICKe, J., and WhitField, A. G. W. (1954): The Nephrotic Syndrome Associated with Thrombosis of the Renal Veins, Lancet, ii, 1208.

Derow, H. A., Schlesinger, M. J., and Savitz, K. A. (1939): Chronic Progressive Occlusion of the Inferior Vena Cava and the Renal and Portal Veins, Arch. intern. Med., 63, 626.

HarRison, C. V., Milne, M. D., and Steiner, R. E. (1956): Clinical Aspects of Renal Vein Thrombosis, Quart. J. Med., 25, 285.

Hasson, J., Berkman, J. I., Parker, J. G., and RIFKIN, H. (1957): A Clinicopathologic Study of Chronic Renal Vein Thrombosis in Adults, Ann. intern. Med., 47, 493.

Pollak, V. E., Kark, R. M., Pirani, C. L., Shafter, H. A., and MUEHRCKE, R. C. (1956): Renal Vein Thrombosis and the Nephrotic Syndrome, Amer. J. Med., 21, 496.

Rowntree, L. G., Fitz, R., and Gerachty, J. T. (1913): The Effects of Experimental Chronic Passive Congestion on Renal Function, Arch. intern. Med., 11, 121.

ShatTock, S. G. (1913): Occlusion of the Inferior Vena Cava as a Result of Internal Trauma (Dissecting Varix?), Proc. roy. Soc. Med., 6, 126.

\title{
HISTIOCYTOSIS $\mathrm{X}$
}

\author{
W. H. H. Garvie, M.B., F.R.C.S. \\ Late Surgical Registrar \\ Royal Marsden Hospital, London, S.W.3.
}

THE SUGgestion that eosinophilic granuloma, Schüller-Christian's disease and Letterer-Siwe's disease are but various expressions of the same illness was advanced by Farber (1941), Green and Farber (1942) and Jaffe and Lichtenstein (1944). The disease entity was called "Histiocytosis X" by Lichtenstein (1953). This integration of the three diseases has not, however, been accepted by everyone (McGavran and Spady, 1960).
The following case is reported because it gives further evidence in support of this unifying concept. Some additional information about this rare condition is also presented.

\section{Case Report}

T.Y., a female infant aged 15 months, was admitted to a London hospital on December 20,1963. She had been in good health until seven weeks before her 


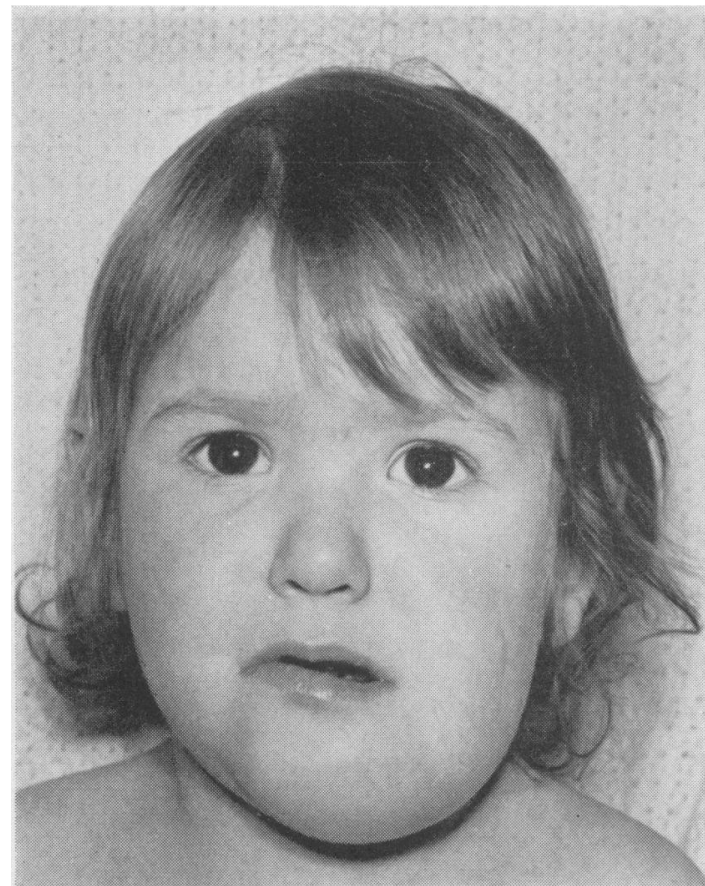

Fig. 1.-Showing marked facial asymmetry due to diffuse enlargement of the left mandible. admission. At this time a swelling developed in the region of the ramus of the left mandible and rapidly increased in size. It was apparently painful and the overlying skin was hot and red. This was considered to be an inflammatory swelling associated with an erupting left lower molar tooth. A course of penicillin was given but this brought about no improvement. She was referred to hospital and X-ray of the mandible showed that the bone from the mid-line to the angle on the left side had been replaced by an expanding cystic lesion. There was cortical destruction of the inferior aspect of the mandible in the area of the cyst. No definite diagnosis could be made from the radiological appearances. Following admission to hospital the newly erupted tooth was extracted. The tooth socket was replaced by soft, reddish-grey granulation tissue. A biopsy was taken. On histological examination this was found to consist of large reticulum cells, frequently multinucleate, with large hyperchromatic nuclei and showing occasional mitosis. Eosinophils were present in large number scattered among the Iarger cells. Foam cells and multinucleate giant cells were not seen. A diagnosis of Histiocytosis $\mathbf{X}$ (eosinophilic granuloma) was made and the infant was transferred to the Royal Marsden Hospital on January 8, 1964.

Examination on admission revealed an apparently healthy child, normally developed for her age. There was marked facial asymmetry due to a diffuse enlargement of the left mandible (Fig. 1). Inside the mouth a fleshy swelling replaced the left lower alveolus (Fig. 2). One small lymph node was palpable in the left submandibular group.

Investigations:- Skeletal survey did not demon- 8 strate any other bony lesion. The chest $\mathrm{X}$-ray was

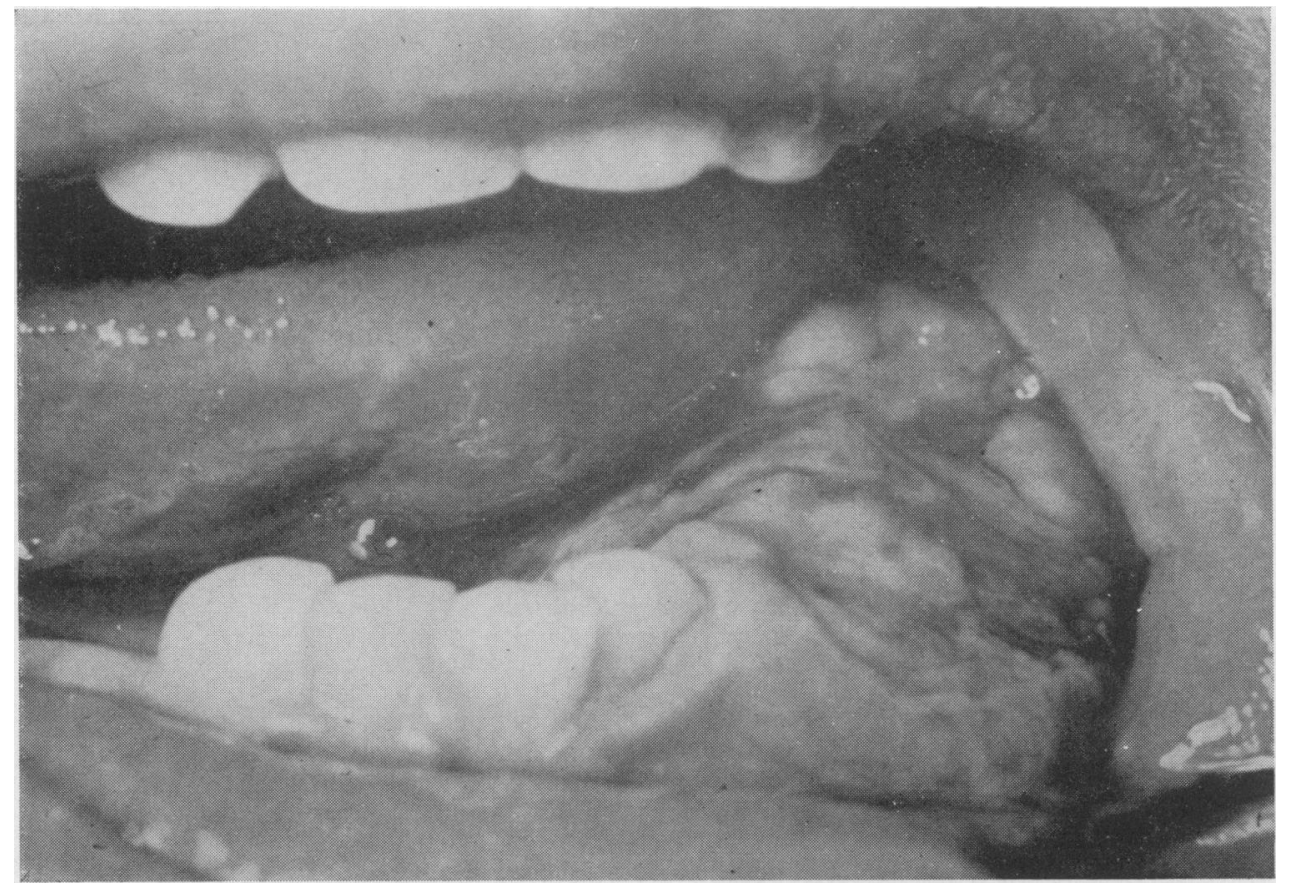

Fig. 2.-A fleshy tumour replaces the left lower alveolus. 


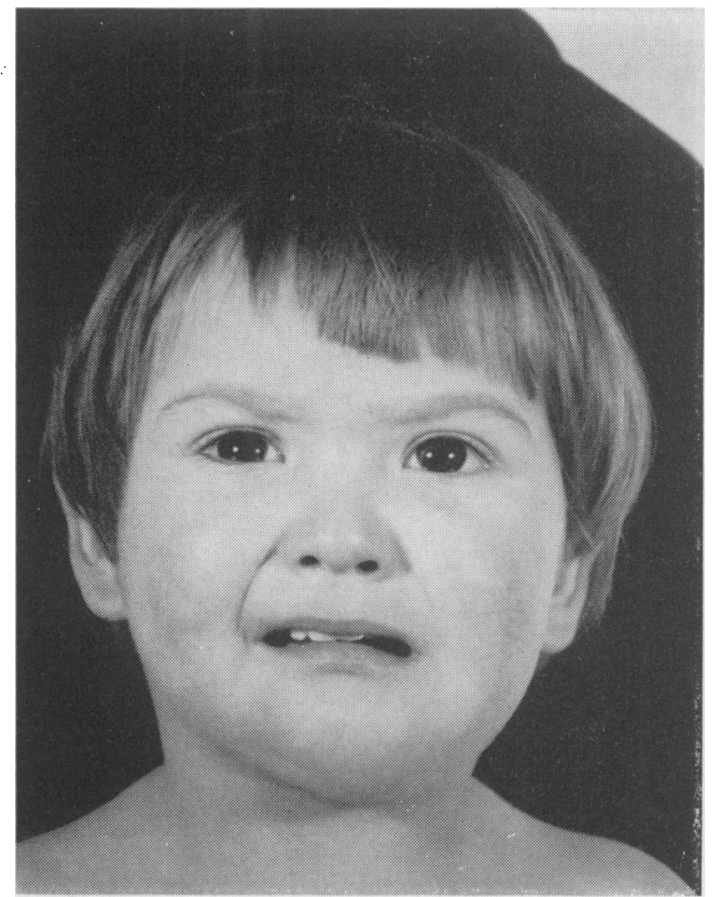

FIG. 3.-Following completion of the local radiotherapy and after three weeks treatment with prednisone.

normal. Hb $89 \%$ (13.2 g.) WBC $8,500 /$ cu. mm., a normal differential. The temperature was not elevated.

The left mandibular area was irradiated and a total dose of $1,500 \mathrm{r}$ was given in 44 days. The bony lesion decreased in size but no change was noted in the enlarged lymph node which was within the irradiated field. A further skeletal survey carried out during the course of radiotherapy demonstrated an osteolytic lesion in the supraorbital region of the right frontal bone. Lymph nodes became palpable in both cervical chains and in the axillæ. Because the disease appeared to be spreading, following completion of the radiotherapy, treatment with prednisone, $2.5 \mathrm{mg}$. twice daily, was started. Her condition improved. The lymph nodes became smaller and the skull lesion ceased to enlarge. The mandibular lesion continued to decrease in size (Fig. 3). This improvement was maintained for six weeks.

At the beginning of April, 1964 she developed a purulent discharge from the lefit ear. On examining the ear, a granulomatous lesion was found in the external auditory canal. This was biopsied and, on histological examination, the appearances were found to be identical with that of the biopsy of the mandible. Culture of the pus yielded a growth of Staph. pyogenes. The appropriate broad-spectrum antibiotic was prescribed. Coincident with the onset of the aural discharge the infants' condition deteriorated. Cervical, axillary and inguinal lymph nodes enlarged rapidly and the liver and spleen became palpable. Crops of petechiæ appeared on the scalp. The temperature, which had previously been normal, rose sharply to $104^{\circ} \mathrm{F}$. $\left(40^{\circ} \mathrm{C}\right.$.) and remained elevated. Chest X-rays were normal, blood cultures were sterile and examination of the CSF revealed no abnormality.
The hæmoglobin level, which had shown only slight variation since admission, fell rapidly to $53 \%$. A transfusion of $300 \mathrm{ml}$. of blood was given but the following day the hæmoglobin level was still $53 \%$. A few days later a further transfusion of $400 \mathrm{mls}$. of blood was given. The hæmoglobin level following this was found to be $46 \%$. The infant became transiently jaundiced and developed severe hæmoglobinuria. The prednisone dose was increased and further broad-spectrum antibiotics prescribed but the down-hill course continued. She died on April 19, 1964. The total duration of the illness was just over five months. The acute terminal phase lasted two weeks.

Necropsy:-In the skeleton, granulomatous lesions were found in the mandible, the right frontal bone and in the petrous part of the left temporal bone. The lungs were infiltrated. In the abdomen, the spleen was grossly enlarged and weighed $447 \mathrm{~g}$. (normal=30 g.). Numerous granulomatous deposits were present throughout the splenic substance. The liver was only slightly enlarged and was not involved in the disease process. A few deposits were present in the proximal large bowel but the stomach and small intestine were free from disease. Cervical, axillary, mediastinal and cœliac lymph nodes were all involved, the largest nodes measuring $3 \mathrm{~cm}$. in diameter. Deposits were present in the red bone marrow but did not entirely replace this structure. The central nervous system was free from disease and the pituitary gland was normal.

\section{Discussion}

The relationship between eosinophilic granuloma, Schüller-Christian's disease and LettererSiwe's disease depends on the essential histological similarity between the three conditions and the occurrence of cases which show an intermediate or variable clinical picture. That the three conditions are histologically similar is well established following the observations of Wallgren (1940), Farber (1941), Green and Farber (1942), Jaffe and Lichtenstein (1944) and Lichtenstein (1953). However, similar tissue manifestations cannot, by themselves, be used to support a theory of common ætiology. Many granulomatous processes of dissimilar æatiology have similar tissue changes (McGavran and Spady, 1960). It follows that the inter-relationship of the three conditions will only be proved if cases showing an intermediate or variable clinical picture are found. It is for this reason that this case is presented.

At the onset, the disease process appeared to be localised and the infant was in good general health. Clinically the condition resembled eosinophilic granuloma. There was an incomplete response to irradiation and groups of lymph nodes became involved. This state was maintained for several weeks and a designation of SchüllerChristian's disease would have been applicable. The terminal stage was rapid and resembled Letterer-Siwe's disease. Clinically, therefore, the whole spectrum of the disease Histiocytosis $\mathbf{X}$ is seen in the one patient. This is additional evidence that eosinophilic granuloma, SchüllerChristian's disease and Letterer-Siwe's disease are but different manifestations of a single disease entity. 
That cortisone may be of value in the treatment of Schüller-Christian's disease was suggested by Blahd, Levy and Bassett (1951). In the present case prednisone may have been of temporary benefit. The maximal effect was on the lymph glands. Although the mandibular lesion continued to improve this was probably due to the radiotherapy as no decrease in size was noted in the other bony lesion.

A purulent discharge from the ear is frequently mentioned in previous case reports and this is often associated with the presence of granulation tissue in the external auditory canal. It has not been considered of much importance but it is so common a finding that it must form part of the clinical picture. Histological examination of the granulations in this case identified the tissue as being similar to the lesions elsewhere in the patient.

Anæmia is a common finding in this disease and its occurrence has not been completely explained. At post-mortem examination in this case, granulomatous deposits were found in the bone marrow but they were not so extensive as to completely replace the blood forming elements. That the bone marrow is capable of responding even when involved in the disease process was demonstrated by Wallgren (1940) who found a reticulocyte count of $12.6 \%$ in a patient with a hæmoglobin of $32 \%$. The failure to respond to blood transfusion was surprising but this type of progressive anæmia in spite of blood replacement has been reported (Abt and Denenholz, 1936). In this case obvious hæmolysis of the red cells was taking place. It may be that a hæmolytic type of anæmia is usually present in this disease. However, no reference to this can be found in the literature.

I am indebted to Mr. M. H. Harmer for permission to publish this case report.

\section{REFERENCES}

ABT, A. F., and DenenholZ, E. J. (1936): LettererSiwe's Disease. Splenohepatomegaly Associated with Widespread Hyperplasia of Non-lipoid Storing Macrophages; Discussion of the so-called Reticulo-endotheliosis. Amer. J. Dis. Child., 51, 499.

BlahD, W. H., Levy, M. S., and Bassett, S. H. (1951): A Case of Hand-Schüller-Christian Syndrome treated with Cortisone. Ann. intern. Med., 35, 927.

FARBER, S. (1941): The Nature of "Solitary or 8 Eosinophilic Granuloma" of Bone. Amer. J. Path., 3 17, 625.

GreEN, W. T., and FARBER, S. (1942): "Eosinophilic or Solitary Granuloma" of Bone. J. Bone Jt. Surg., 24, 499.

JAFFE, H. L., and LiCHTENSTEIN, L. (1944): Eosino- $\mathscr{C}$ philic Granuloma of Bone. Arch. Path., 37, 99.

LiCHTENSTEIN, L. (1953) : Histiocytosis X. Integration of Eosinophilic Granuloma of Bone, "LettererSiwe disease", and "Schüller-Christian disease" as T related Manifestations of a Single Nosologic Entity. A.M.A. Arch. Path., 56, 84.

MCGavRan, M. H., and SPADY, H. A. (1960): Eosinophilic Granuloma of Bone, J. Bone Jt Surg 42A, 979.

WALlGREN, A. (1940): Systemic Reticuloendothelia Granuloma. Non-lipoid Reticuloendotheliosis and Schüller-Christian Disease. Amer. J. Dis. Childz? 60, 471 .

\title{
ARTERIAL OCCLUSION TREATED WITH STREPTOKINASE
}

\author{
A Report of Two Cases
}

M. L. Clark, M.B., M.R.C.P.

Margaret Howell, M.B., B.S.

\author{
Christine Hawkey, M.Sc. \\ R. S. O. REES, M.B., M.R.C.P., D.M.R.D.
}

J. StubBs, Ph.D., F.R.C.S.

St. George's Hospital and Medical School, London, S.W.1.

The Plasminogen activator streptokinase was first given intravenously to human volunteers by Tillett, Johnson and McCarty (1955) and subsequently has been used as a thrombolytic agent, case reports having recently been published in British journals (Cotton, Flute and Tsapogas, 1962; McNicol, Reid, Bain, and Douglas, 1963; Verstræte, Amery and Vermylen, 1963). Streptokinase may be administered by one of two methods; either intravenous infusion starting with a calculated loading dose, thus providing a high level of streptokinase throughout the circulation, or by local infusion into the affected artery proximal to the actual occlusion. The second method has the advantage that, whilst using relatively small doses, a high concentration of the drug can be brought into close contact with the thrombus, although the level of streptokinase in the general circulation remains too low to cause a coagulation defect. 